\title{
The iSchools
}

\author{
Ronald L. Larsen, Dean \\ School of Information Sciences \\ University of Pittsburgh \\ Dedicated to the memory of Raymond von Dran \\ Dean of the School of Information Studies \\ Syracuse University, 1995-2007
}

\begin{abstract}
Information Schools ("iSchools") address the relationship between information, technology, and people. This is characterized by a commitment to learning and understanding the role of information in human endeavors. The ischools take it as given that expertise in all forms of information is required for progress in science, business, education, and culture. This expertise must include understanding of the uses and users of information, as well as information technologies and their applications.
\end{abstract}

As of 2008, twenty-one iSchools in the U.S. and Canada have joined the "iCaucus", a forum in which ischools' deans collaborate to further their collective interests through focused events such as the "iConference" and resources of broader interest such as the iSchools web site.

Keywords: information school, information science, library science, education, Interdisciplinarity, information technology, informatics, information studies

\section{Origins}

In 1988, Toni Carbo, dean of the School of Library and Information Sciences (now the School of Information Sciences) at the University of Pittsburgh, formed the "Gang of Three," including her decanal colleagues at Syracuse University's School of Information Studies (Donald Marchand) and Drexel University's College of Information Science and Technology (Richard Lytle). Within the next couple of years, the dean of the School of Communication, Information, and Library Studies at Rutgers University (Richard Budd) joined the group, making it a "Gang of Four." The Gang grew out of informal conversations at a meeting of the Association for Library and Information Science Education (ALISE). Each of the schools offered graduate Library \& Information Science (LIS) and a variety of "other" programs, including undergraduate information science, telecommunications, journalism, etc. The objective was to share information and to foster development of a community of colleagues addressing such questions as "How do you explain information science (IS) to your provost?" The Gang met informally into the mid-1990s. 
In 2001, the group was reconstituted under Toni's leadership at a meeting in Pittsburgh. Participants included deans from Syracuse University (Raymond von Dran), Drexel University (David Fenske), the University of Washington's Information School (Michael Eisenberg), and the University of Michigan's School of Information (John King). With that meeting, the "Gang of Five" was formed.

Beginning in 2003, Gang membership grew with the addition of deans from the Graduate School of Library and Information Science at the University of Illinois, the School of Information and Library Science at the University of North Carolina, the College of Information at Florida State University, the School of Informatics at Indiana University, and the School of Information at the University of Texas, bringing it to the "Gang of Ten." By this point, the informal name was becoming unwieldy and a bit inappropriate, particularly as continued growth was anticipated. Through the leadership of deans John King, the late Raymond von Dran, and Michael Eisenberg, the group's agenda became more focused on building a sense of identity and community among the "information schools," or "iSchools."

Typically, the group met twice per year. Meetings, hosted by one of the deans, included private discussions among the deans as well as open conversations with faculty of the host school, and usually an informal reception or lunch. During the deans-only sessions, the agenda focused on challenging administrative, programmatic, and planning issues, in addition to the continuing interest in explaining IS better to our non-IS colleagues. The sessions also provided an opportunity to learn about the curriculum and research of each school. An early goal was to nurture the development of a critical mass of faculty across the schools to undertake collaborative research.

The group was formally named "the iSchools Caucus" (more casually referred to as the iCaucus), and its membership grew rapidly with the addition of:

- The School of Communication, Information, and Library Studies Rutgers University (rejoining)

- The School of Information University of California, Berkeley

- The Donald Bren School of Information and Computer Sciences University of California, Irvine

- The Graduate School of Education and Information Studies University of California, Los Angeles

- The College of Information Sciences and Technology Pennsylvania State University 
- The College of Computing Georgia Institute of Technology

- The School of Library and Information Science Indiana University

- The College of Information Studies University of Maryland

- The Faculty of Information University of Toronto

And in 2008, two more institutions joined:

- The Heinz School Carnegie Mellon University

- The School of Information Systems Singapore Management University

As a board member of the Computing Research Association (CRA), King introduced the iSchools Caucus to the CRA IT Deans Group, founded in 2000 at the Snowbird meeting and chaired by Peter Freeman (Georgia Tech). In 2008, the name of the CRA group was shortened with majority approval to the "CRA Deans" group. The CRA Deans group provides a broad forum for leaders of IT schools, colleges, and institutes to share experiences, strategies, opportunities, and concerns. It illuminates issues and seeks common ground leading to a coherent and unified voice for the academic and research communities, and to the general public. A substantial majority of the iSchool deans have joined the CRA Deans group in order to assure that information-related issues are appropriately reflected in the group's evolving agenda.

\section{Motivation}

The emergence and evolution of iSchools was triggered by the explosive growth in digital information. In a 2003 study $^{1}$, Peter Lyman and Hal Varian estimated that about 5 exabytes $\left(5 \times 10^{18}\right)$ of new information was generated in 2002 worldwide, with a growth rate of about $30 \%$ per year. They note that 5 exabytes "is equivalent in size to the information contained in 37,000 new libraries the size of the Library of Congress book collections." A 2007 study by IDC ${ }^{2}$ concluded that the worldwide production of information in 2006 exceeded 161 exabytes, increasing at a compound annual growth rate of $57 \%$. While only a small fraction of this information is accessible online ( $<2 \%$ by some estimates), it still represents an enormous and increasing amount of information that presents major challenges (and opportunities) in information management, access, and preservation. 
Marcia Bates defines "the domain of information science [as] the universe of recorded information that is selected and retained for later access," and posits that applied information science is "primarily concerned with the form and organization of information, its underlying structure, and only secondarily with its content." ${ }^{3}$ Add to this the study of human use of information and the design and development of the technological tools to utilize information, and an understanding of the domain of the iSchools emerges. Bates succinctly states these through three driving questions:

- What are the features and laws of the recorded-information universe? (physical question)

- How do people relate to, seek, and use information? (social question)

- How can access to recorded information be made most rapid and effective? (design question)

"The iSchools are interested in the relationship between information, technology, and people. This is characterized by a commitment to learning and understanding the role of information in human endeavors. The iSchools take it as given that expertise in all forms of information is required for progress in science, business, education, and culture. This expertise must include understanding of the uses and users of information, as well as information technologies and their applications." (From the iSchools web site www.ischools.org, 2008.)

\section{Positioning}

The "identity debate" has a long tradition in information studies and it influenced the formation of the iSchools as a group. It takes on many forms and has multiple dimensions. Wanda Orlikowski and Suzanne lacono ${ }^{4}$ argued for a theoretical focus on IT artifacts and laid out five relevant conceptualizations:

- Tool view (e.g., a productivity enhancer);

- Proxy view (e.g., surrogate measures such as return on investment);

- Ensemble view (e.g., technology embedded in a socio-economic system);

- Computational view (e.g., models and algorithms); and

- Nominal view (e.g., studies of broad impacts such as outsourcing).

Ron Weber ${ }^{5}$ posited, "the identity of a discipline is established through the contributions it makes to theory." He went on to suggest that he could find "only one class of phenomena for which theories sourced from other disciplines seemed deficient - namely, phenomena associated with building conceptual models and designing databases."

Another facet of the identity discussion has been the attempt to draw boundaries. Izak Benbasat and Robert $\mathrm{Zmud}^{6}$ summarized some of this line of thought as placing claim on three necessary and sufficient criteria: a central character, distinctiveness, and temporal continuity. They argued that a dominant design for the information systems discipline "has yet to be realized" and that this hinders the field's legitimacy. They affirmed the centrality of the IT 
artifact, placing the notion in a broad context including understanding capabilities and practices, human behaviors, usage, and impacts.

Robert Galliers ${ }^{7}$ pushed back on Benbasat and Zmud, arguing that boundaries and disciplinary cores emerge naturally as a field evolves. In IS, forces shaping this evolution include such topics as the digital divide, globalization, and IT in the developing world, resulting in a broadening of the locus of study to include societal, policy, and ethical issues. He suggested adopting a "transdisciplinary" perspective on the field of IS. The following table adapts Galliers' characterization for IS to the domain of the ischools.

\begin{tabular}{|l|l|l|}
\hline & Disciplinarity & Trans-disciplinarity \\
\hline Boundary & Organization & Society \\
\hline Central Artifact & IT & People/Information \\
\hline Focus & Inward & Outward \\
\hline Scope & Narrow & Broad \\
\hline Reference Disciplines & Org-Behavior, CS, etc. & IS, LIS, Telecommunications \\
\hline Properties & Defined & Emergent \\
\hline Inter-disciplinary & A threat & An opportunity \\
\hline
\end{tabular}

Gerardine DeSanctis ${ }^{8}$ reflected on the increasing pervasiveness of information technology, observing that "knowledge and creative use are no longer the sole domain of specialists." This has shifted the dominant functional role of information professionals from development to leadership and support, and put many in strategic business positions. As information professionals take on these new roles, technical skills must be supplemented with new competencies in human relations and organizational effectiveness. As DeSanctis observed, "the institutional paradox for IS is that the domain has become of interest to many faculty groups yet the sole purview of none." While, perhaps, not the sole purview, this is, most certainly, the primary purview of the iSchools. Rather than focusing on a bounded "domain," DeSanctis argued for a "focus on the questions" and observed that these have historically generated excitement and impact in IS.

Daniel Robey ${ }^{9}$ continued the call for a "more flexible identity for IS" that avoids "the lure of a dominant research paradigm." He suggested a pursuit of "pragmatic legitimacy" that casts IS as a "valued partner in intellectual exchanges with our external constituents: the governing bodies, business executives, university officials, and scholars from other disciplines who are the key actors in IS's organizational field."

John King and Kalle Lyytinen ${ }^{10}$ acknowledged that the IS field lacks a theoretic core and has been "haunted by feelings of inadequacy" for 30 years. They proposed an alternative model for establishing legitimacy, grounded in three drivers:

- Salience of issues studied;

- Production of strong results; and 
- Maintenance of plasticity.

They offered an alternative view of the core of the discipline as a "market of ideas" where the IS field is defined as "the study of the design and management of information and associated technologies in organized human enterprise." Rather than accepting the argument that theory should provide the foundation, they suggest, rather, that theory "to the extent that it has a role, is in the service of producing strong results."

King ${ }^{11}$ sums up this discussion of identity, observing that iSchools "straddle the academy's ancient engagement with information and the contemporary challenges of ubiquitous information affecting all aspects of society. ... The [iSchool] movement is emergent; its equilibrium can only be found in an essential tension among competing visions in a world of rapid technical and social change. [iSchool] identity is elusive and will remain so for the foreseeable future."

\section{Empowerment}

Studying at an iSchool immerses students in this dynamic and emerging "iField," where they confront the issues, opportunities, and challenges of an information society in the $21^{\text {st }}$ century, in all their richness, controversy, and ambiguity. The iField addresses the fundamental issue of harnessing the incredible flow of information for the betterment of humanity.

The iField also empowers people in other fields to create, find, store, manipulate, and share information in useful forms. It may be unique in that, despite its elusive core, its subject, information, is at the heart of what individuals, organizations, and societies need in order to advance human endeavors, from acting to zoology. The iField's most visible and viable outcome is the delivery of the right information at the right time to the right people in the right form.

\section{Organization}

The iSchools were founded as a consortium to establish broad recognition of the iField and its importance to society. In this role, they sought to position a group of academic institutions to identify, clarify, and speak to the major issues, challenges, and driving questions at the nexus of information, technology, and society. While a relatively small number of universities took the lead in establishing an organization with this goal, those who share the goal and contribute to its achievement go far beyond the small collection of organizers. The defining characteristics of iSchools (whether iCaucus members or not) include:

- an interest in the relationship between information, technology, and people;

- a commitment to learning and understanding the role of information in human endeavors;

- a recognition that expertise in all forms of information is required for progress in science, business, education, and culture; and 
- a belief that this expertise must include understanding of the uses and users of information, as well as information technologies and their applications.

The collective efforts of the iSchools (e.g., the iConference, the web site, and special projects) are managed by the iCaucus. Members of the iCaucus pay an annual fee and have one vote on iCaucus decisions. The iCaucus charter specifies its membership criteria. Candidate memberships are reviewed by a membership committee and voted on by the full iCaucus membership. While not rigid, iCaucus members are expected to have substantial sponsored research activity, to engage in the training of future researchers (usually through an active, research-oriented doctoral program), and a commitment to progress in the information field. Each iSchool's representative to the iCaucus (usually a dean) is expected to report to the chief academic officer of the parent institutions.

The iSchools sponsor the iConference as a forum for faculty, students, and researchers to share their work and to develop their extended network of colleagues. The conference runs 3-4 days and the program typically includes a doctoral colloquium, poster and paper sessions, panels, roundtables, and social events. The first iConference was held at Penn State in September $2005 .^{12}$ Subsequent iConferences were hosted by the University of Michigan and UCLA, with the 2009 iConference being hosted by UNC Chapel Hill.

\section{Vision}

As a relatively straightforward example, consider an iSchool's approach to information assurance, an issue of contemporary salience, for which we seek to produce strong results while adapting to changing conditions. When viewed as a technological issue, scientists and engineers are likely to focus on topics such as cryptography, steganography, public key infrastructure, and intrusion detection, or, in other words, technical areas in which they are likely to have significant interest and expertise. The same set of issues viewed from the perspective of librarians may be more likely to draw attention to questions of identification, authentication, provenance, and access. A social scientist, on the other hand, may focus on issues of confidentiality, authentication, privacy, and integrity. So who is right? Clearly, they all are. Information assurance is a multidisciplinary problem with extraordinarily complex and interrelated technical, policy, and social challenges. An iSchool provides the venue that enables scholars from a variety of contributing disciplines to leverage their individual insights, perspectives, and interests, informed by a rich, "trans-disciplinary" community.

But trans-disciplinary collaboration is not a natural act. Not only does each discipline bring to the table a set of values, goals, models, economics, and ethics that have evolved slowly and in relative isolation over an extended period of time within their discipline, but also they must interact with and respond to the interests of external bodies. These are not always aligned in ways that foster rapid agreement. 
- Values - some will argue that strength is derived from information access, while others contend that power is founded on information control.

- Goals - some argue for increasing safety and security by way of imposing limits and locks, while others opine that justice and accountability are advanced through dialogue and debate.

- Models - some see information access primarily as a societal responsibility, where others view it dominantly as a business opportunity.

- Economics - information is expensive to create and publish, but cheap to replicate and distribute.

- Ethics - some argue that ethics are trumped by the realities of the real world, while others rebut that they are motivated by that very same world.

The complex interaction among the disciplines, when allowed to play out in an iSchool, provides a rich environment for the education of information professionals. Exploiting the very tensions that arise among the various constituencies enriches the creative insight of each. Among the issues feeding such creative dialogue are topics such as:

- Intellectual property rights and its relation to fair use;

- Open, extensible systems as an alternative to proprietary, closed designs;

- Access to publicly-funded information balanced against legitimate security requirements;

- Assuring ethical public policy when the need for expediency feels overwhelming; and

- Recognizing the need for both selective government secrecy and accountability through open records.

While the resolution of these issues is ultimately expressed in society's evolving social contract, the ischools serve a vital role by:

- Preparing the next generation of information professionals;

- Informing the relevant social and political structures regarding the implications and use of information technologies;

- Assuring that debates surrounding the development of policy and law are properly informed by sound scholarship;

- Advising society of the potential consequences of policy alternatives;

- Interpreting opportunities and implications of policy alternatives; and

- Remaining, themselves, engaged students of a highly dynamic landscape of change.

So what is an iSchool in the $21^{\text {st }}$ century? Informed by decades of debate and responding to exceptionally rapid changes in technology and uncertainty in public policy, iSchools foster the development of an intellectual space where true interdisciplinarity plays out. In so doing, they introduce a range of challenges to traditional university structures and practices regarding organizational boundaries, promotion and tenure policies, doctoral education, research legitimacy, etc., as they create an environment where issues of information are addressed 
systematically, regardless of disciplinary heritage or presumed 'ownership'. In this way, iSchools respond to the salient issues of the time by stressing the production of strong results. They are in a constant state of adaptation within their core competencies, while building necessary bridges among disciplines. The iSchools recognize that the near-term future will be shaped largely by industry, so their applied research agenda is strongly influenced by these emerging needs and directions. But the iSchools lead industry and government in the study of timeless, recurring, theoretical questions, and educate the next generation of information professionals who will shape the future of a global information society.

\section{Recognition}

Von Dran was a dynamic and powerful force in both the development of the School of Information Studies at Syracuse University and the formation of the iSchools movement. In his own words, "Information schools are advancing a common notion that it's information, and not simply the technology, that is the driver. The information field must harness a number of disciplines and approaches that critically affect the relevance, timeliness, accessibility, and quality of information. These schools bring together the various aspects of technology, management, policy, and usability, among others, for the benefit of people everywhere."

In his honor, the iSchools have established an award to recognize others who have demonstrated Ray's commitment to excellence and leadership. The award is presented at the iConference and includes a monetary award and an opportunity for the award winner to share his or her vision of the challenges and opportunities confronting the information profession to conference participants.

\section{Acknowledgment}

The author gratefully acknowledges the assistance of Toni Carbo and Jonathan Grudin in reconstructing the historical timeline for the iSchools and of Maeve Reilly for improving the readability of this article.

\section{References}

${ }^{1}$ Lyman, Peter and Hal Varian. How much information? 2003. Berkeley, CA: School of Information Management and Systems at the University of California at Berkeley, 2003 (http:// www2.sims.berkeley.edu/research/projects/how-much-info-2003/).

${ }^{2}$ IDC. A Forecast of Worldwide Information Growth Through 2010. Framingham, MA: IDC, 2007 (http://www.emc.com/collateral/analyst-reports/expanding-digital-idc-white-paper.pdf).

${ }^{3}$ Bates, Marcia J. "The Invisible Substrate of Information Science." Journal of the American Society for Information Science and Technology (JASIST), 1999: 50(12), 1043-1050

(http://www.gseis.ucla.edu/faculty/bates/substrate.html). 
${ }^{4}$ Orlikowski, Wanda J. and C. Suzanne lacono. "Research Commentary: Desperately Seeking the 'IT' in IT Research - A Call to Theorizing the IT Artifact." Information Systems Research, vol. 12, no. 2 (2001): 121134 (http://isr.journal.informs.org/cgi/content/abstract/12/2/121).

${ }^{5}$ Weber, Ron. "Still Desperately Seeking the IT Artifact." In Information Systems, The State of the Field, by John Leslie King and Kalle Lyytinen, 43-54. West Sussex, England: John Wiley \& Sons, Ltd, 2006 (reprinted from MIS Quarterly, available online at http://www.misq.org/archivist/vol/no27/issue2/EdCommentsV27N2.pdf).

${ }^{6}$ Benbasat, Izak and Robert W. Zmud. "The Identity Crisis within the IS Discipline: Defining and Communicating the Discipline's Core Properties." In Information Systems, The State of the Field, by John Leslie King and Kalle Lyytinen, 55-70. West Sussex, England: John Wiley \& Sons, Ltd., 2006.

${ }^{7}$ Galliers, Robert D. "Change as Crisis or Growth? Toward a Trans-disciplinary View of Information Systems as a Field of Study: A Response to Benbasat and Zmud's Call for Returning to the IT Artifact." In Information Systems, The State of the Field, by John Leslie King and Kalle Lyytinen, 147-162. West Sussex, England: John Wiley \& Sons, Ltd., 2006.

${ }^{8}$ DeSanctis, Gerardine. "The Social Life of Information Systems Research: A Response to Benbasat and Zmud's Call for Returning to the IT Artifact." In Information Systems, The State of the Field, by John Leslie King and Kalle Lyytinen, 163-182. West Sussex, England: John Wiley \& Sons, Ltd., 2006.

${ }^{9}$ Robey, Daniel. "Identity, Legitimacy and the Dominant Research Paradigm: An Alternative Prescription for the IS Discipline." In Information Systems, The State of the Field, by John Leslie King and Kalle Lyytinen, 183-190. West Sussex, England: John Wiley \& Sons, Ltd., 2006.

${ }^{10}$ King, John Leslie, and Kalle Lyytinen. "Nothing at the Center?: Academic Legitimacy in the Information Systems Field." In Information Systems, The State of the Field, by John Leslie King and Kalle Lyytinen, 233-266. West Sussex, England: John Wiley \& Sons, Ltd., 2006.

${ }^{11}$ King, John Leslie. "Identity in the I-School Movement." Bulletin of the American Society for Information Science and Technology, April/May 2006 (http://www.asis.org/Bulletin/Apr-06/king.html).

${ }^{12}$ Harmon, Glynn. "The First I-Conference of the I-School Communities." Bulletin of the American Society for Information Science and Technology (ASIS\&T), April/May 2006 (http://www.asis.org./Bulletin/Apr$06 /)$. 